\title{
GPC-Based Gust Response Alleviation for Aircraft Model Adapting to Various Flow Velocities in the Wind Tunnel
}

\author{
Yuting Dai and Chao Yang \\ School of Aeronautic Science and Engineering, Beihang University, Beijing 100191, China \\ Correspondence should be addressed to Yuting Dai; yutingdai@buaa.edu.cn
}

Received 21 February 2015; Revised 27 April 2015; Accepted 17 May 2015

Academic Editor: Sakdirat Kaewunruen

Copyright (C) 2015 Y. Dai and C. Yang. This is an open access article distributed under the Creative Commons Attribution License, which permits unrestricted use, distribution, and reproduction in any medium, provided the original work is properly cited.

\begin{abstract}
A unified autoregressive (AR) model is identified, based on the wind tunnel test data of open-loop gust response for an aircraft model. The identified AR model can be adapted to various flow velocities in the wind tunnel test. Due to the lack of discrete gust input measurement, a second-order polynomial function is used to approximate the gust input amplitude by flow velocity. Afterwards, with the identified online aeroelastic model, the modified generalized predictive control (GPC) theory is applied to alleviate wing tip acceleration induced by sinusoidal gust. Finally, the alleviation effects of gust response at different flow velocities are estimated based on the comparison of simulated closed-loop acceleration with experimental open-loop one. The comparison indicates that, after gust response alleviation, the wing tip acceleration can be reduced up to $20 \%$ at the tested velocities ranging from $12 \mathrm{~m} / \mathrm{s}$ to $24 \mathrm{~m} / \mathrm{s}$. Demonstratively, the unified control law can be adapted to varying wind tunnel velocities and gust frequencies. It does not need to be altered at different test conditions, which will save the idle time.
\end{abstract}

\section{Introduction}

Dynamic response of aircrafts induced by gust or turbulence may reduce the ride quality, and it increases the structural load [1]. Researchers found that the gust loads can be successfully reduced when gust load alleviation systems are applied to aircrafts $[2,3]$. In fact, gust load alleviation (GLA) active control is an effective tool to reduce the dynamic gust response, with a minor increasing of aircraft's weight. For example, they are used in aircraft such as the B-52 and C5 $[4,5]$. In order to guarantee real aircraft's safety, gust response alleviation systems are designed and validated using many wind-tunnel tests $[6,7]$. The control law design is an important part in the design process of GLA active technique. Most researches about GLA control law design were concentrated on PID method and linear quadratic Gauss (LQG) theory [8]. $H_{\infty}$ optimal control and $\mu$ synthesis are also effective robust control methods to account for variations in the mathematical model. However, all those control laws are based on a known theoretical continuous aeroelastic model. Model-based control laws may fail when the aeroelastic model is not accurate enough. Alternatively, a data-based control law design may be suitable for gust load alleviation. The data-based autoregressive model is a good tool to construct a discrete model without the theoretical continuous mathematical model [9]. It is found to be effective in aeroelastic modeling for online flutter prediction [10]. Therefore, the controller design can be conducted on a data-based AR model. This is the significant advantage of generalized predictive control (GPC) method. GPC can tackle not only with the theoretical continuous model but also for discrete AR model. Notably, it is demonstrated to be a useful controller for linear-parameter-varying nonlinear system [11]. Based on the above advantages, the data-based GPC is welcome to aeroelastic active control, for both gust load alleviation and flutter suppression [12,13]. It is validated to be effective for gust load alleviation in the simulation [12].

$\mathrm{Wu}$ et al. conducted a gust response wind tunnel test and they designed a PID controller to alleviate the wing tip acceleration. The open-loop response data was measured at a specific velocity under sinusoidal gust. After all the open-loop responses are measured ranging from $12 \mathrm{~m} / \mathrm{s}$ to $24 \mathrm{~m} / \mathrm{s}$, the closed-loop responses are also measured at these conditions by a PID controller. In this test, there are two challenged problems. Because there are some discrepancies of theoretical aeroelastic model and real aircrafts [14], 
the best PID parameters on theoretical model may not work well on real wind tunnel test model. They have to be trialed several times in the wind tunnel test. The other problem is that the amplitude of discrete sinusoidal gust disturbance was not measured in this test, which makes the comparison between theoretical results and testing ones difficult. Hence, the data-based GPC is designed to the wind gust response alleviation test. The basis for generalized predictive control is the identification of an autoregressive mode. While the gust input used for AR model identification is unknown, it varies with test velocity. Moreover, if we identify one AR model at one test condition, we will need to alter the control law for other different test conditions. It will be a waste of time to switch the control law manually in the wind tunnel test.

Hence, a unified GPC controller is developed. It is adapting to all the test conditions, used for gust response alleviation in the wind tunnel test. The sections of this paper are as follows. First, the standard GPC control law is introduced, and then it is modified to adapt to varying wind tunnel test velocities. Finally, a wind tunnel test of an aircraft model is employed to validate the alleviation effect.

\section{Control Law Design for Gust Response Alleviation}

In this section, firstly, the standard GPC design method for gust response alleviation is derived at a specific flow velocity and at a specific gust frequency. Afterwards, the standard GPC method is modified to adapt to varying flow velocities.

2.1. Gust Response Alleviation at a Fixed Flow Velocity. GPC is a data-based method for control law design. The design of it begins by identifying an autoregressive (AR) model, based on open-loop input and output data [12]. After the AR model is identified, a controller is acted on it to minimize the prediction of the system response in the future. In this design process, the control law is not represented by a state-space equation form but is described as a sequence of discrete inputoutput data.

When an external excitation exists, a time-invariant multi-input-multi-output AR model is written as [12]

$$
\begin{aligned}
\mathbf{y}(k)= & \boldsymbol{\alpha}_{1} \mathbf{y}(k-1)+\boldsymbol{\alpha}_{2} \mathbf{y}(k-2)+\cdots+\boldsymbol{\alpha}_{p} \mathbf{y}(k-p) \\
& +\boldsymbol{\beta}_{0} \mathbf{u}(k)+\boldsymbol{\beta}_{1} \mathbf{u}(k-1)+\cdots+\boldsymbol{\beta}_{p} \mathbf{u}(k-p) \\
& +\boldsymbol{\gamma}_{0} \mathbf{d}(k)+\boldsymbol{\gamma}_{1} \mathbf{d}(k-1)+\cdots+\boldsymbol{\gamma}_{p} \mathbf{d}(k-p),
\end{aligned}
$$

where integer $p$ is called the order of the AR model. $\mathbf{y}(k-p)$ is the output of the model and $\mathbf{d}(k-p)$ is the measured disturbance. Since the gust response in the wind tunnel test is excited by a sinusoidal-moving gust generator, the level of signal-to-noise ratio is large enough to omit noise $\mathbf{d}(k-p)$. $\mathbf{u}(k-p)$ is the system input at the time of $k-p$. It contains two parts. One is the deflection of control surfaces $\mathbf{u}_{c}$, the other is the gust velocity on the aircraft model in the wind tunnel test. As mentioned above, the discrete gust is generated by a biplane which moves as a sinusoidal function. Hence, the gust input $u_{g}$ has the following form:

$$
u_{g}=A_{v} \sin \omega t
$$

where $A_{v}$ is the gust amplitude; it is related with flow velocity. $\omega$ is the known gust frequency.

Substituting (2) to (1) and dividing the input signal $\mathbf{u}$ into two parts, $\mathbf{u}_{c}$ and $u_{g}$, then (1) can be modified as

$$
\begin{aligned}
\mathbf{y}(k)= & \boldsymbol{\alpha}_{1} \mathbf{y}(k-1)+\boldsymbol{\alpha}_{2} \mathbf{y}(k-2)+\cdots+\boldsymbol{\alpha}_{p} \mathbf{y}(k-p) \\
& +\boldsymbol{\beta}_{0}^{\prime} \mathbf{u}_{c}(k)+\boldsymbol{\beta}_{1}^{\prime} \mathbf{u}_{c}(k-1)+\cdots+\boldsymbol{\beta}_{p}^{\prime} \mathbf{u}_{c}(k-p) \\
& +\gamma_{10} A_{v} \sin \omega t(k)+\gamma_{11} A_{v} \sin \omega t(k-1)+\cdots \\
& +\gamma_{1 p} A_{v} \sin \omega t(k-p)
\end{aligned}
$$

When we keep the flow velocity fixed under one test condition, the gust amplitude can be regarded as a constant. Rearranging (3), we can get

$$
\begin{aligned}
\mathbf{y}(k)= & \boldsymbol{\alpha}_{1} \mathbf{y}(k-1)+\boldsymbol{\alpha}_{2} \mathbf{y}(k-2)+\cdots+\boldsymbol{\alpha}_{p} \mathbf{y}(k-p) \\
& +\boldsymbol{\beta}_{0}^{\prime} \mathbf{u}_{c}(k)+\boldsymbol{\beta}_{1}^{\prime} \mathbf{u}_{c}(k-1)+\cdots+\boldsymbol{\beta}_{p}^{\prime} \mathbf{u}_{c}(k-p) \\
& +\boldsymbol{\gamma}_{0}^{\prime} \mathbf{u}_{d}(k)+\boldsymbol{\gamma}_{1}^{\prime} \mathbf{u}_{d}(k-1)+\cdots \\
& +\boldsymbol{\gamma}_{p}^{\prime} \mathbf{u}_{d}(k-p)
\end{aligned}
$$

where $\gamma_{0}^{\prime}=A_{v} \gamma_{10}$ and $\mathbf{u}_{d}(k)=\sin \omega t(k)$. By this rearranging, the gust disturbance $\mathbf{u}_{d}$ is known to us. Hence, when the responses of wing tip acceleration and deflections of control surfaces $\mathbf{u}_{c}$ are measured, the regressive relationship of input and output in the $l$ time steps can be written as

$$
\mathbf{Y}=\overline{\mathbf{Y}} \mathbf{V}
$$

where $\mathbf{Y}=[\mathbf{y}(0), \mathbf{y}(1), \ldots, \mathbf{y}(l-1)]$ and $\mathbf{V}$ is formed of the discrete time series of $\mathbf{u}_{c}, \mathbf{u}_{d}$, and $\mathbf{y}$. It is written as

V

$$
=\left[\begin{array}{ccccccc}
\mathbf{u}_{d}(0) & \mathbf{u}_{d}(1) & \mathbf{u}_{d}(2) & \cdots & \mathbf{u}_{d}(p) & \cdots & \mathbf{u}_{d}(l-1) \\
\mathbf{u}_{c}(0) & \mathbf{u}_{c}(1) & \mathbf{u}_{c}(2) & \cdots & \mathbf{u}_{c}(p) & \cdots & \mathbf{u}_{c}(l-1) \\
0 & \mathbf{v}(0) & \mathbf{v}(1) & \cdots & \mathbf{v}(p-1) & \cdots & \mathbf{v}(l-2) \\
0 & 0 & \mathbf{v}(0) & \cdots & \mathbf{v}(p-2) & \cdots & \mathbf{v}(l-3) \\
& & & \ddots & \cdots & \cdots & \vdots \\
& & & & \mathbf{v}(0) & \cdots & \mathbf{v}(l-p-1)
\end{array}\right],
$$

where the matrix element $\mathbf{v}(k)$ is the combination of gust disturbance signal, input signal, and output signal at the $k$ th time step. That is, $\mathbf{v}(k)=\left[\mathbf{u}_{d}(k), \mathbf{u}_{c}(k), \mathbf{y}(k)\right]^{T} . \overline{\mathbf{Y}}$ is the vector of observer Markov parameters to be identified. Associating $\overline{\mathbf{Y}}$ with (4), we can get

$$
\overline{\mathbf{Y}}=\left[\begin{array}{llllllllllll}
\boldsymbol{\gamma}_{0}^{\prime} & \boldsymbol{\beta}_{0}^{\prime} & \gamma_{1}^{\prime} & \boldsymbol{\beta}_{1}^{\prime} & \boldsymbol{\alpha}_{1} & \boldsymbol{\gamma}_{2}^{\prime} & \boldsymbol{\beta}_{2}^{\prime} & \boldsymbol{\alpha}_{2} & \cdots & \boldsymbol{\gamma}_{p}^{\prime} & \boldsymbol{\beta}_{p}^{\prime} & \boldsymbol{\alpha}_{p}^{\prime}
\end{array}\right]
$$


The solution of $\overline{\mathbf{Y}}$ is calculated by employing a least square algorithm. That is [12],

$$
\overline{\mathbf{Y}}=\mathbf{y} \mathbf{V}^{+}=\mathbf{y} \mathbf{V}^{T}\left[\mathbf{V} \mathbf{V}^{T}\right]^{-1}
$$

After the parameter $\bar{Y}$ of the AR model at the $k$ th time step in (4) is identified according to the past $l$ time steps, the control system is switched on from the $k+1$ time step. It drives the control surface to move. In the closed-loop system, the deflection of control surface is still denoted as $\mathbf{u}_{c}$. Then in the future $h_{p}$ time steps, the response of the future time step $j$ th can be also represented as a linear combination of three parts. One part is the response of future $j$ time steps and the last $p$ time steps. The second part is the deflection of control surface $\mathbf{u}_{c}$ in the future $h_{c}$ time steps and in the last $p$ time steps. The third part is the gust disturbance in the future $j$ time steps and the past $p$ time steps. The regressive relationship of future response is written as

$$
\begin{aligned}
\mathbf{y}(k+j)= & \boldsymbol{\alpha}_{1}^{j} \mathbf{y}(k-1+j)+\boldsymbol{\alpha}_{2}^{j} \mathbf{y}(k-2+j)+\cdots \\
& +\boldsymbol{\alpha}_{p}^{j} \mathbf{y}(k-p+j)+\boldsymbol{\beta}_{0}^{\prime} \mathbf{u}_{c}(k+j) \\
& +\boldsymbol{\beta}_{0}^{\prime 1} \mathbf{u}_{c}(k-1+j)+\cdots+\boldsymbol{\beta}_{0}^{\prime j} \mathbf{u}_{c}(k) \\
& +\boldsymbol{\beta}_{1}^{\prime j} \mathbf{u}_{c}(k-1)+\cdots+\boldsymbol{\beta}_{p}^{\prime j} \mathbf{u}_{c}(k-p) \\
& +\boldsymbol{\gamma}_{0}^{\prime} \mathbf{u}_{d}(k+j)+\boldsymbol{\gamma}_{0}^{\prime 1} \mathbf{u}_{d}(k-1+j)+\cdots \\
& +\boldsymbol{\gamma}_{0}^{\prime j} \mathbf{u}_{d}(k)+\boldsymbol{\gamma}_{1}^{\prime j} \mathbf{u}_{d}(k-1)+\cdots \\
& +\boldsymbol{\gamma}_{p}^{\prime j} \mathbf{u}_{d}(k-p) .
\end{aligned}
$$

In the above equation, the regressive coefficients are represented by combinations of the observer Markov parameters in (7). That is,

$$
\begin{aligned}
& \text { elements in } \mathbf{A}: \boldsymbol{\alpha}_{p}^{j}=\boldsymbol{\alpha}_{p+1}^{j-1}+\boldsymbol{\alpha}_{1}^{j-1} \boldsymbol{\alpha}_{p} \text {, } \\
& \text { elements in } \mathbf{T} \text { and } \mathbf{B}: \boldsymbol{\beta}_{0}^{\prime j}=\boldsymbol{\beta}_{1}^{\prime j-1}+\boldsymbol{\alpha}_{1}^{j-1} \boldsymbol{\beta}_{0}^{\prime}, \boldsymbol{\beta}_{p}^{\prime j}= \\
& \boldsymbol{\beta}_{p+1}^{\prime j-1}+\boldsymbol{\alpha}_{1}^{j-1} \boldsymbol{\beta}_{p}^{\prime} \text {, } \\
& \text { elements in } \mathbf{D}_{f} \text { and } \mathbf{D}_{p}: \boldsymbol{\gamma}_{0}^{\prime j}=\gamma_{1}^{\prime j-1}+\boldsymbol{\alpha}_{1}^{j-1} \boldsymbol{\gamma}_{0}^{\prime}, \boldsymbol{\gamma}_{p}^{\prime j}= \\
& \boldsymbol{\gamma}_{p+1}^{\prime j-1}+\boldsymbol{\alpha}_{1}^{j-1} \gamma_{p}^{\prime} .
\end{aligned}
$$

The goal for control law design is to alleviate the gust response in the wind tunnel test. Hence, in the framework of GPC strategy, it is required to minimize the predicted wing tip acceleration in the future $h_{p}$ time steps. Hence, the objective of the optimized control command in the next $h_{c}$ time steps is written as [12]

$$
\min \left(\mathbf{y}_{h_{p}}^{T}(k) \mathbf{R} \mathbf{y}_{h_{p}}(k)+\mathbf{u}_{h c}^{T}(k) \mathbf{Q} \mathbf{u}_{h c}(k)\right)
$$

where

$$
\begin{gathered}
\mathbf{y}_{h p}(k)=\left[\begin{array}{c}
\mathbf{y}(k) \\
\mathbf{y}(k+1) \\
\vdots \\
\mathbf{y}\left(k+h_{p}-1\right)
\end{array}\right], \\
\mathbf{u}_{h c}(k)=\left[\begin{array}{c}
\mathbf{u}_{c}(k) \\
\mathbf{u}_{c}(k+1) \\
\vdots \\
\mathbf{u}_{c}\left(k+h_{c}-1\right)
\end{array}\right], \\
\mathbf{u}_{d}(k) \\
\mathbf{u}_{d}(k+1) \\
\vdots \\
\mathbf{d}_{g f}(k)=\left[\begin{array}{c}
\mathbf{u}_{d}\left(k+h_{p}-1\right)
\end{array}\right] .
\end{gathered}
$$

It is a typical optimal control problem. Equation (10) means that we want to find a control command to obtain a weighted minimized response in the future $h_{p}$ time steps, with relatively low control energy. By solving the optimal problem shown in (10), the optimal deflection of control surface at the time step $k+1$ is written as

$$
\begin{aligned}
& \mathbf{u}_{c}(k+1)=\left\{-\left(\mathbf{T}^{T} \mathbf{R} \mathbf{T}+\mathbf{Q}\right)^{\dagger} \mathbf{T}^{T} \mathbf{R}\left(\mathbf{B} \mathbf{u}_{p}(k-p)\right.\right. \\
& \left.\left.+\mathbf{A y}_{p}(k-p)+\mathbf{D}_{p} \mathbf{d}_{g p}(k-p)+\mathbf{D}_{f} \mathbf{d}_{g f}(k)\right)\right\}_{r c},
\end{aligned}
$$

where $\mathbf{T}, \mathbf{B}, \mathbf{A}, \mathbf{D}_{p}$, and $\mathbf{D}_{f}$ can be calculated in advance and be written into the control program for online gust load alleviation. $\mathbf{R}$ and $\mathbf{Q}$ are the weighting matrices for predicted response and control effort, respectively. In the wind tunnel test, the wing tip acceleration has to be alleviated. And the aileron and elevator are selected as the control surfaces for gust alleviation.

2.2. Gust Response Alleviation at Varying Flow Velocities. The basis of standard GPC is to identify an AR model according to the known input-output data. Hence, when GPC is employed to gust response alleviation, it is assumed that the sinusoidal gust input is already known, not only its frequency, but also its amplitude. The gust frequency is easy to get from measuring the angular velocity of the gust generator. When the flow velocity in the wind tunnel is fixed, the value of gust amplitude can be merged to the identified coefficients $\gamma_{p}^{\prime}$, as shown in (4). However, when the flow velocity varies, the corresponding gust input has been changed. In this case, another AR model should be identified. In this case, a different control law should be redesigned for this different test condition. Therefore, we have to switch the control law frequently from one test condition to another. This may waste a lot of time in a real wind tunnel test. The idea in this paper is to identify a unified AR model to apply only one GPC controller to all the test velocities in the wind tunnel. 


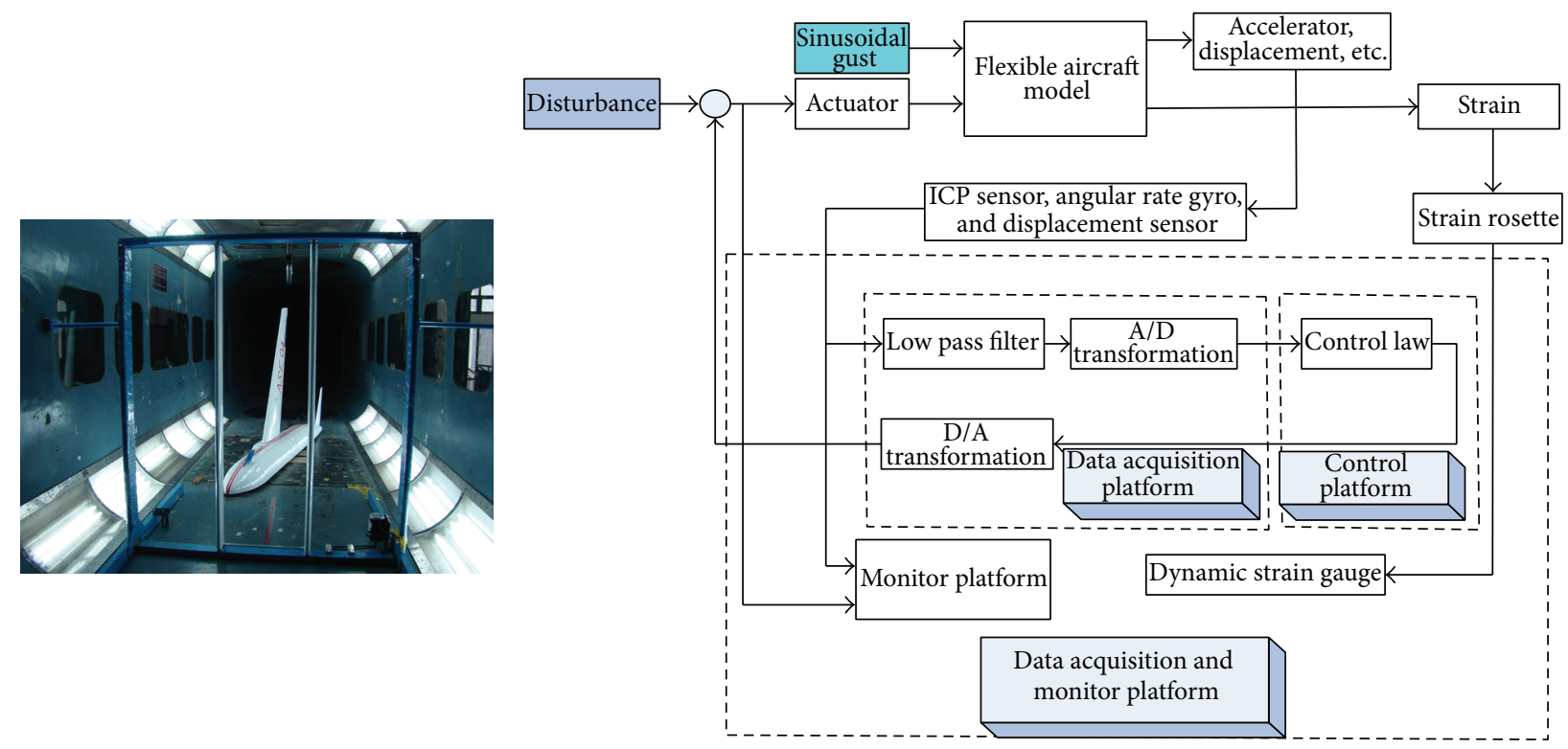

FIGURE 1: The elastic aircraft model and experimental control flowchart.

As mentioned above, the gust velocity in the wind tunnel test is not measured. Moreover, it is difficult to deduce the gust velocity from the comparison between theoretical response and experimental one. Hence, the relationship between gust velocities and flow velocities is unknown for us. In order to solve this problem, the relationship between gust input and flow velocity is approximated in this current work.

A direct way is to employ a fitting function to represent the relationship between gust input and flow velocity. For the sake of simplicity, a second-order polynomial function is applied to represent it by the linear combinations of flow velocities. That is,

$$
u_{g}=A_{0} \sin \omega_{i} t+A_{1} V_{0} \sin \omega_{i} t+A_{2} V_{0}^{2} \sin \omega_{i} t,
$$

where $\omega_{i}$ is the gust frequency at different test conditions. To combine this expression to the standard AR model, we increase the dimensions of gust disturbance from one to three. Therefore, the gust disturbance in (4) is written as a vector:

$$
\mathbf{u}_{d}(k)=\left[\sin \omega_{i} t(k), V_{0} \sin \omega_{i} t(k), V_{0}^{2} \sin \omega_{i} t(k)\right]^{T} .
$$

By this approximation, we can represent the gust disturbance by varying flow velocities. The predicted control law also needs to be modified to adjust to three gust inputs, shown in (12). Hence, a unified control law can be adapted to different flow velocities, and there is no need to switch the control laws from one test condition to another.

\section{Application Example}

3.1. The Open-Loop Gust Response Wind Tunnel Test. In 2011, the gust response and alleviation test for the half-span aircraft model was conducted in the FD-09 Wind Tunnel [8]. The dimension of the wind tunnel is $3 \times 3 \mathrm{~m}$ in the test section.
The pitch-plunge supporting mechanism was mounted below the wind tunnel floor without disturbance to the airflow. A feedback control law is acting on the actuator of the elevator, to stabilize the pitch and plunge motions. The responses are measured by the NI PXI-4472B NI data acquisition equipment, with the acquisition frequency of $200 \mathrm{~Hz}$. The mounted aircraft model and gust response alleviation flowchart are shown in Figure 1. In this test, the open-loop gust response is measured first. And then a PI control law is acted on the aileron for gust load alleviation.

In this current work, the open-loop experimental gust response is used for $\mathrm{AR}$ model identification. Afterwards, the developed GPC control law is designed based on the AR model and it is switched on after several time steps. The simulated closed-loop gust response is compared with the experimental open-loop one.

In order to guarantee the aircraft model's safety, the experimental flow velocity is from $12 \mathrm{~m} / \mathrm{s}$ to $24 \mathrm{~m} / \mathrm{s}$, much far away from the flutter velocity of $31 \mathrm{~m} / \mathrm{s}$. The frequency of gust generator changes from $1.0 \mathrm{~Hz}$ to $6.0 \mathrm{~Hz}$ with a fixed increasing step of $0.5 \mathrm{~Hz}$. In the open-loop gust response test, the gust generator upwards the aircraft model is switched on all the time. After the gust frequency keeps still, the flow velocity increases to a given value with a fixed increasing step of $2 \mathrm{~m} / \mathrm{s}$. At a fixed velocity and gust frequency, we measured the accelerations and deflections of control surfaces for 15 seconds. A Fourier transformation is conducted on all the 15 -second data to obtain the response amplitude in the frequency domain. The amplitude of the open-loop wing tip acceleration at different velocities and frequencies is shown in Figure 2 and Table 1.

Figure 3 is the closed-loop acceleration by the PI controller in the wind tunnel test at the velocity of $18 \mathrm{~m} / \mathrm{s}$. From the comparison, it can be seen that the controller cannot suppress the wing tip acceleration at a low gust frequency of 
TABLE 1: The open-loop wing tip acceleration data due to sinusoidal gust in the wind tunnel test.

\begin{tabular}{|c|c|c|c|c|c|c|c|}
\hline Frequency: $\mathrm{Hz}$ & $\begin{array}{c}\text { Acceleration at } \\
12 \mathrm{~m} / \mathrm{s}: \mathrm{g}\end{array}$ & $\begin{array}{c}\text { Acceleration at } \\
14 \mathrm{~m} / \mathrm{s}: \mathrm{g}\end{array}$ & $\begin{array}{c}\text { Acceleration at } \\
16 \mathrm{~m} / \mathrm{s}: \mathrm{g}\end{array}$ & $\begin{array}{c}\text { Acceleration at } \\
18 \mathrm{~m} / \mathrm{s}: \mathrm{g}\end{array}$ & $\begin{array}{c}\text { Acceleration at } \\
20 \mathrm{~m} / \mathrm{s}: \mathrm{g}\end{array}$ & $\begin{array}{c}\text { Acceleration at } \\
22 \mathrm{~m} / \mathrm{s}: \mathrm{g}\end{array}$ & $\begin{array}{c}\text { Acceleration at } \\
24 \mathrm{~m} / \mathrm{s}: \mathrm{g} \\
\end{array}$ \\
\hline 1.0 & 0.10 & 0.11 & 0.12 & 0.17 & 0.17 & 0.18 & 0.18 \\
\hline 1.5 & 0.21 & 0.35 & 0.29 & 0.28 & 0.29 & 0.40 & 0.42 \\
\hline 2.0 & 0.70 & 0.69 & 0.79 & 0.70 & 0.79 & 0.83 & 0.86 \\
\hline 2.5 & 0.55 & 0.47 & 0.80 & 1.09 & 0.89 & 1.30 & 0.91 \\
\hline 3.0 & 0.42 & 0.61 & 0.85 & 1.28 & 1.34 & 1.56 & 1.82 \\
\hline 3.5 & 0.35 & 0.37 & 0.54 & 1.26 & 1.24 & 1.28 & 1.69 \\
\hline 4.0 & 0.39 & 0.46 & 0.73 & 1.23 & 1.40 & 1.80 & 2.16 \\
\hline 4.5 & 0.32 & 0.44 & 0.61 & 1.06 & 0.91 & 1.28 & 1.82 \\
\hline 5.0 & 0.34 & 0.42 & 0.70 & 0.86 & 1.32 & 1.52 & 1.93 \\
\hline 5.5 & 0.27 & 0.34 & 0.49 & 1.36 & 0.99 & 1.49 & 2.16 \\
\hline 6.0 & 0.33 & 0.41 & 0.53 & 1.41 & 1.23 & 1.97 & 2.48 \\
\hline
\end{tabular}

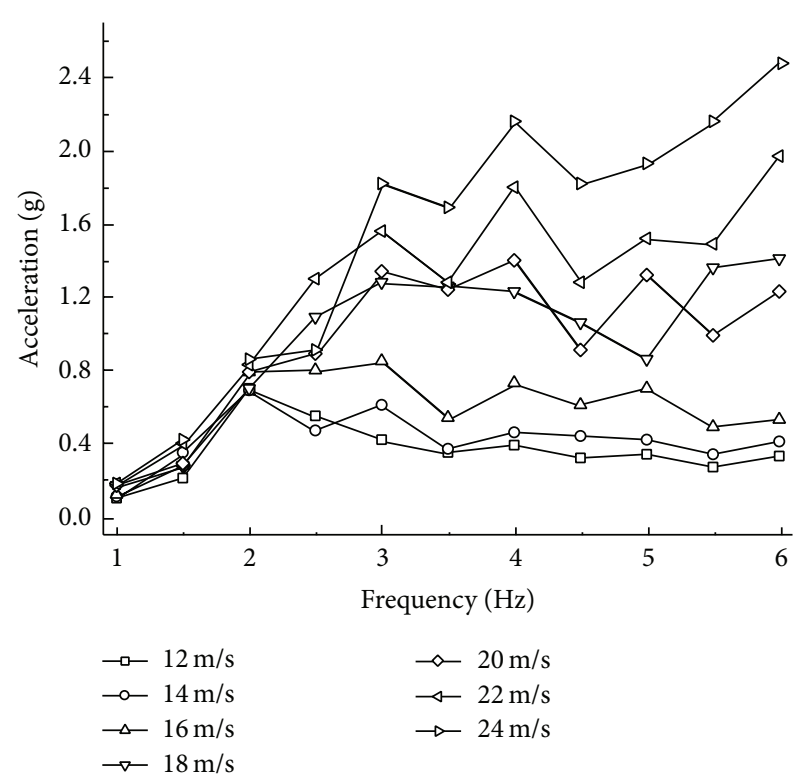

FIGURE 2: The open-loop wing tip acceleration due to sinusoidal gust in the wind tunnel test.

$1 \mathrm{~Hz}$ or at a high gust frequency of $5 \mathrm{~Hz}$. It works even worse at frequencies higher than $5 \mathrm{~Hz}$. The controller alleviates the wing tip acceleration well at other gust frequencies.

\subsection{Gust Response Alleviation at Fixed Flow Velocity and Gust} Frequency. Gust response alleviation by GPC is simulated at a fixed flow velocity and fixed gust frequency. First, the open-loop wing tip acceleration at the flow velocity of $24 \mathrm{~m} / \mathrm{s}$ and gust frequency of $2 \mathrm{~Hz}$ is employed to identify an AR model. Then, a GPC controller at this specified test condition is designed to alleviate the wing tip response. As mentioned above, at a fixed flow velocity, though the gust input is not measured, it can be given as a known form. That is, $u_{d 1}=$ $5 \sin (4 \pi t)$. Some parameters for model identification are set as below: the input-output data length for identification is 400. The order of AR model $p$ is 5. The number of

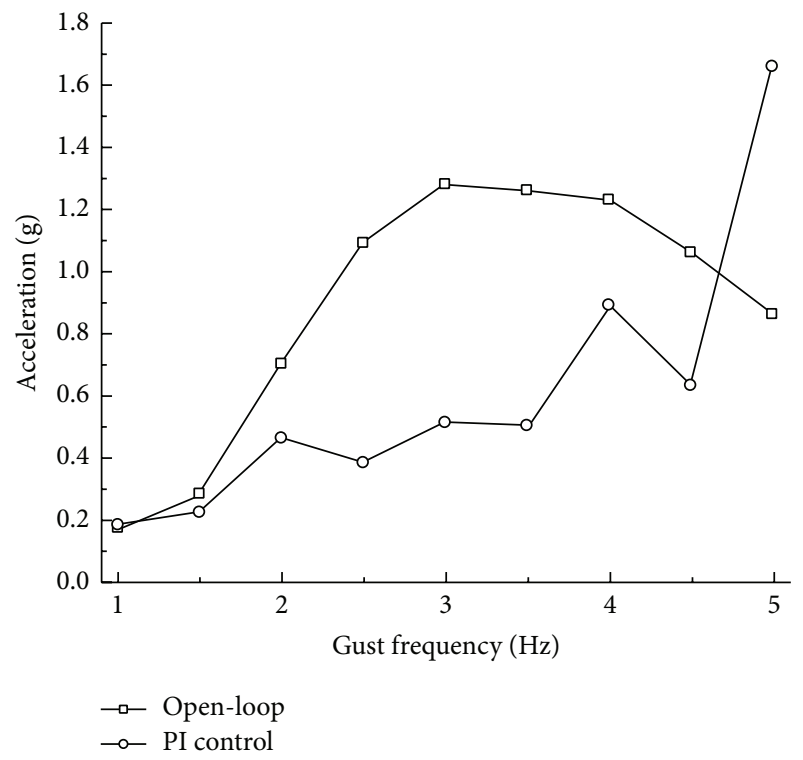

FIGURE 3: Comparison of the experimental open-loop gust response and the closed-loop one by PI controller.

control inputs is 2 . The number of response is one and the number of gust input is one. The weighting matrices for controller design are set to be unity ones. Considering the feasibility of controllers in the wind tunnel test, the lengths of prediction steps and control command steps should not to be too long. Different prediction steps are attempted to choose a better one. Three cases for prediction steps are considered. Their corresponding alleviation results are shown in Table 2. From this table, more prediction steps result in better alleviation results. However, the lengths of prediction window and controller window should not to be too large. It may make controller complicated in the real wind tunnel test. Hence, in the following controller design process, the length of prediction steps $h_{p}$ is fixed to be 5 , and the length of control steps $h_{c}$ is also fixed to be 5 . 
TABLE 2: Alleviation result for different length of prediction steps.

\begin{tabular}{lcccc}
\hline Case number & $\begin{array}{c}\text { Length of } \\
\text { prediction and } \\
\text { control steps }\end{array}$ & $\begin{array}{c}\text { Open-loop } \\
\text { acceleration: }\end{array}$ & $\begin{array}{c}\text { Closed-loop } \\
\text { acceleration: }\end{array}$ & Alleviation factor \\
\hline Case 1 & $h_{p}=1, h_{c}=1$ & 0.858 & 0.823 & $4.1 \%$ \\
Case 2 & $h_{p}=3, h_{c}=3$ & 0.858 & 0.371 & $56.8 \%$ \\
Case 3 & $h_{p}=5, h_{c}=5$ & 0.858 & 0.11 & $87.2 \%$ \\
\hline
\end{tabular}

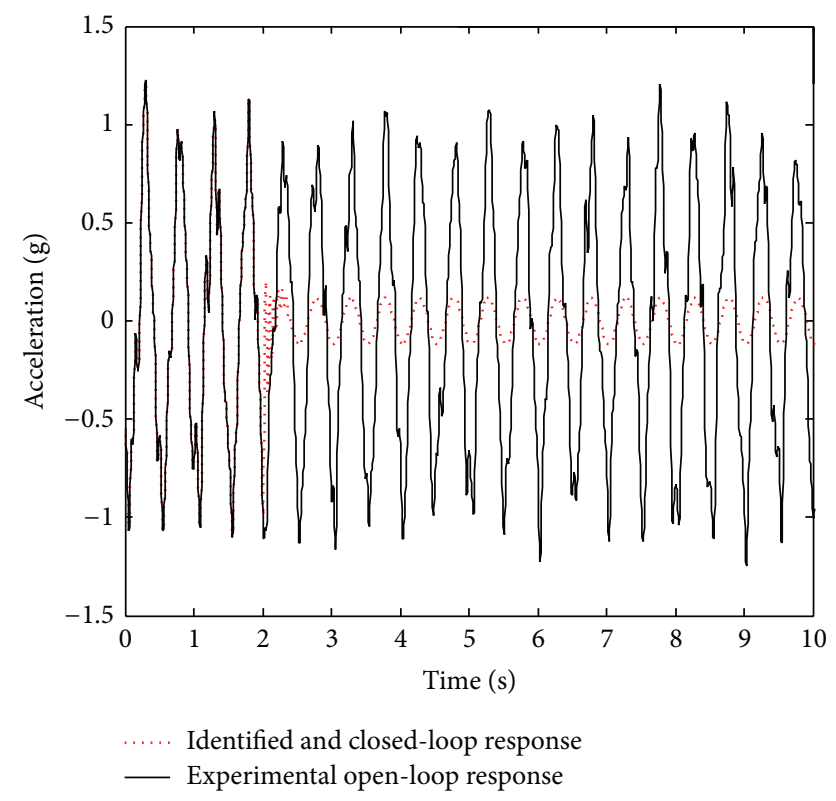

FIGURE 4: The comparison of open-loop and closed-loop accelerations in the time domain for $h_{p}=5, h_{c}=5$.

The gust response alleviation result for Case 3 is shown in Figure 4. The response data in the first 2 seconds is used for AR model identification. After 2 seconds, the prediction controller is switched on. From the figure, it can be seen that the output of the AR model is nearly the same as the experimental acceleration. It indicates that the identified model can represent the aeroelastic behavior at this test condition, and the AR model has a high accuracy for generalized prediction control. After the prediction controller is switched on, the acceleration response reduces to a relatively small value of $0.11 \mathrm{~g}$ in a short time. The response comparison in the frequency domain is shown in Figure 5, and the deflections of control surfaces are shown in Figure 6. The deflection of aileron has a shock on the switch-on time step and then it oscillates between -0.1 degrees and 0.1 degrees in the later time. The experimental deflection of elevator before 2 seconds exceeds 12 degrees. The reason is as follows: the elevator is used for stabilizing the aircraft model in the wind tunnel test, and the model is up-mounted which is unstable at the equilibrium point. Hence, its deflection is a little large before the time of 2 seconds. In the closed-loop simulation, it is only used for active gust response alleviation. Hence, after the time

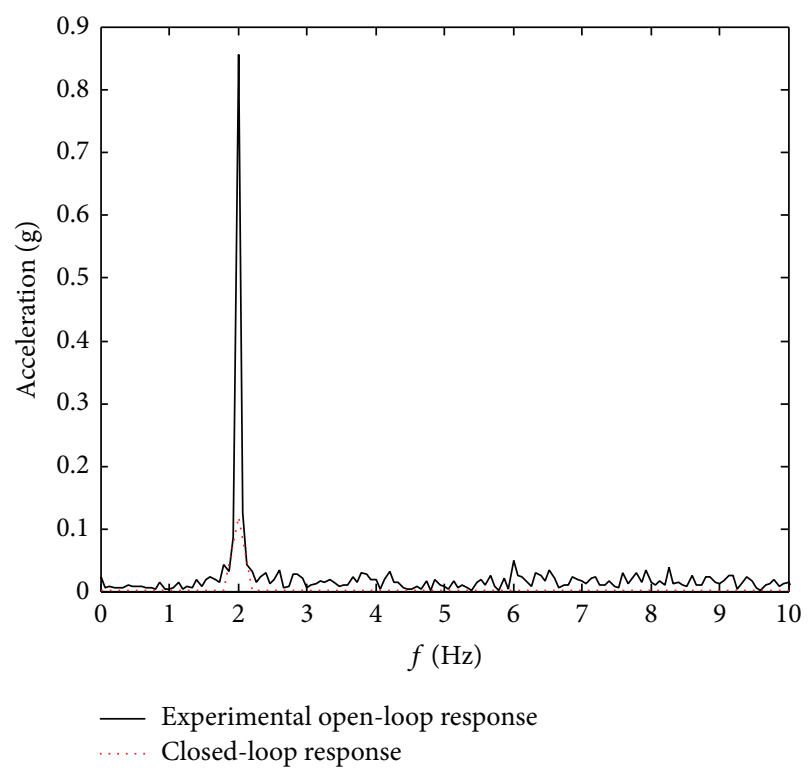

FIGURE 5: The comparison of open-loop and closed-loop accelerations in the frequency domain.

of 2 seconds, its deflection remains oscillating between -0.1 degrees and 0.1 degrees, similar to aileron.

The open-loop responses are measured at each fixed gust frequency and each fixed flow velocity. Hence, the AR model is identified straightforward at each test condition too. The control input in (12) is updated with corresponding test conditions to match the current identified AR model. Therefore, there are $77 \mathrm{AR}$ models and 77 discrete control laws by the standard GPC method. The data length for model identification is set to be 2000 in this case. A Fourier transformation is conducted on the closed-loop response to get the response amplitude. The closed-loop response amplitude at each test condition is shown in Table 3.

When the closed-loop response is larger than the openloop one, it is denoted as bold star in Table 3. From the comparison of Tables 1 and 3 , it can be seen that the standard GPC controller suppresses the acceleration response at most test conditions. However, it is not always effective at all test conditions. At some frequencies of $18 \mathrm{~m} / \mathrm{s}$, the closed-loop response is even larger than the open one. When the data length for identification is only 400 , the alleviation effect is even worse. From the alleviation comparison, the standard GPC controller does not work much better than the PI controller at some low frequencies. Moreover, it needs to 
TABLE 3: Gust response alleviation result at fixed flow velocity and gust frequency.

\begin{tabular}{|c|c|c|c|c|c|c|c|}
\hline Frequency: $\mathrm{Hz}$ & $\begin{array}{c}\text { Acceleration at } \\
12 \mathrm{~m} / \mathrm{s}: \mathrm{g}\end{array}$ & $\begin{array}{c}\text { Acceleration at } \\
14 \mathrm{~m} / \mathrm{s}: \mathrm{g}\end{array}$ & $\begin{array}{c}\text { Acceleration at } \\
16 \mathrm{~m} / \mathrm{s}: \mathrm{g}\end{array}$ & $\begin{array}{c}\text { Acceleration at } \\
18 \mathrm{~m} / \mathrm{s}: \mathrm{g}\end{array}$ & $\begin{array}{c}\text { Acceleration at } \\
20 \mathrm{~m} / \mathrm{s}: \mathrm{g}\end{array}$ & $\begin{array}{c}\text { Acceleration at } \\
22 \mathrm{~m} / \mathrm{s}: \mathrm{g}\end{array}$ & $\begin{array}{c}\text { Acceleration at } \\
24 \mathrm{~m} / \mathrm{s}: \mathrm{g}\end{array}$ \\
\hline 1.0 & 0.10 & 0.11 & 0.11 & 0.15 & 0.16 & 0.15 & 0.12 \\
\hline 1.5 & 0.21 & 0.23 & 0.23 & 0.25 & 0.20 & 0.15 & 0.27 \\
\hline 2.0 & 0.68 & 0.70 & 0.65 & $0.74^{*}$ & 0.74 & 0.42 & 0.59 \\
\hline 2.5 & 0.38 & 0.46 & 0.61 & 0.50 & 0.80 & 0.88 & 0.63 \\
\hline 3.0 & 0.33 & 0.61 & 0.82 & 1.15 & 0.82 & 0.89 & 0.57 \\
\hline 3.5 & 0.27 & 0.35 & 0.53 & 0.70 & 0.40 & 0.45 & 0.86 \\
\hline 4.0 & 0.38 & 0.36 & 0.71 & $1.26^{*}$ & 1.12 & 1.52 & 1.09 \\
\hline 4.5 & 0.21 & 0.30 & 0.41 & 0.70 & 0.82 & 0.60 & 0.57 \\
\hline 5.0 & 0.34 & 0.37 & 0.70 & $0.88^{*}$ & 0.62 & 0.37 & 0.55 \\
\hline 5.5 & 0.18 & 0.27 & 0.48 & 0.40 & 0.80 & 0.78 & 0.30 \\
\hline 6.0 & 0.31 & 0.37 & 0.38 & 0.44 & 0.51 & 0.81 & 0.91 \\
\hline
\end{tabular}

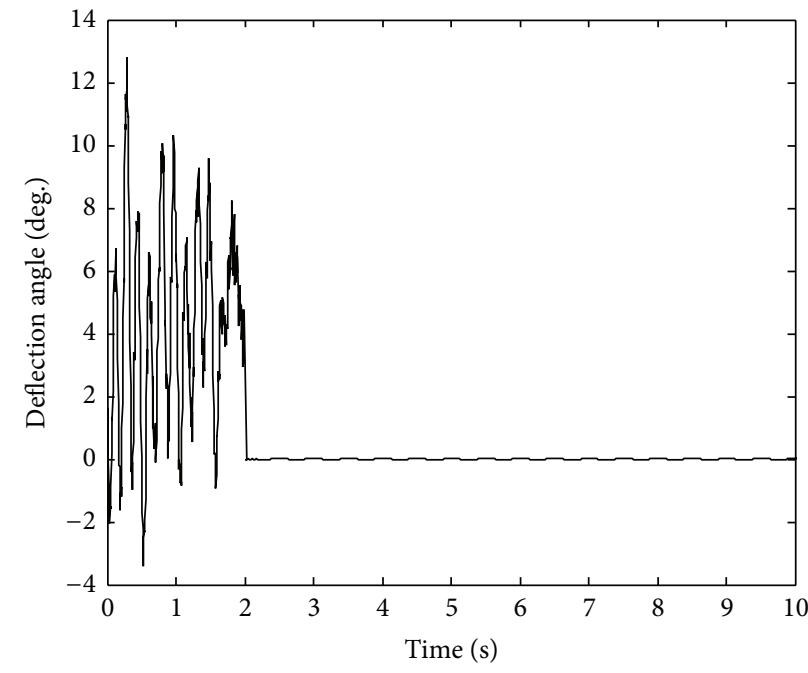

(a) Elevator

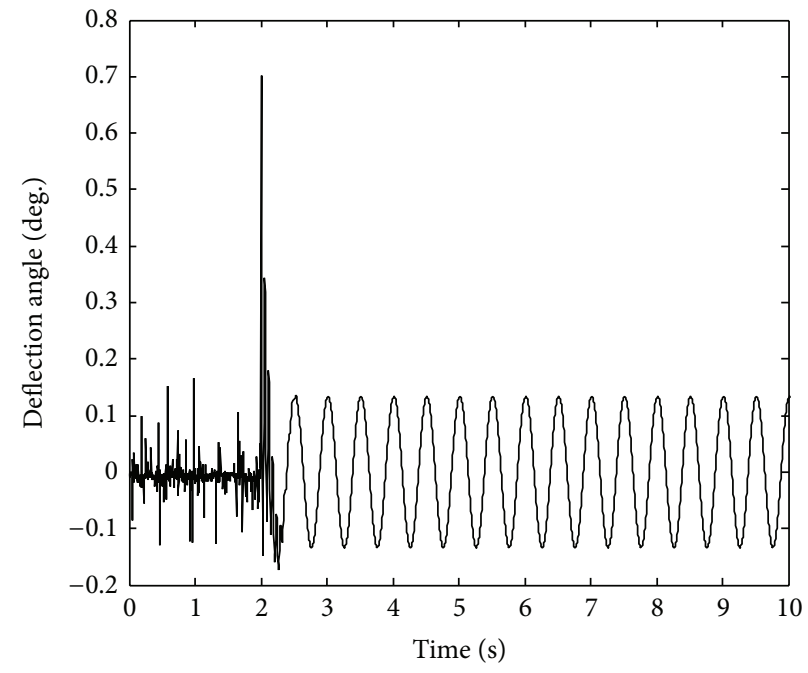

(b) Aileron

Figure 6: Deflections of control surfaces.

identify a new AR model when either the flow velocity or gust frequency changes. This may waste a lot of time to switch the controllers frequently in real wind tunnel test.

3.3. Gust Response Alleviation at Varying Frequencies. In the above section, we need to identify 77 AR models from one test condition to another. In order to reduce the number of identification models, we need to modify the standard GPC design process. A straightforward way is to merge inputoutput data of several test conditions to an entire data series. Then we can identify one unified AR model with these merged data. The difficulty is how to tackle with the varying gust input at different test conditions. From (2), two factors may affect the gust velocity. One is the amplitude; the other is the gust frequency. The gust amplitude may keep constant at a fixed flow velocity. Hence, in this section, we merged the test data of all frequencies at a fixed-flow-velocity condition. Consequently, the gust input series is written as

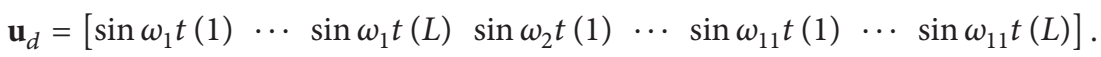

Together with the merged experimental acceleration response, the above gust input is applied to identify one unified AR model at a specified flow velocity. By this approach, there will be 7 AR models for 7 flow velocities from $12 \mathrm{~m} / \mathrm{s}$ to $24 \mathrm{~m} / \mathrm{s}$. At each flow velocity, each AR model is employed to design a GPC control law. The identification and controller 
TABLE 4: Gust response alleviation result for varying frequencies and fixed velocity.

\begin{tabular}{|c|c|c|c|c|c|c|c|}
\hline Frequency: $\mathrm{Hz}$ & $\begin{array}{c}\text { Acceleration at } \\
12 \mathrm{~m} / \mathrm{s}: \mathrm{g}\end{array}$ & $\begin{array}{c}\text { Acceleration at } \\
14 \mathrm{~m} / \mathrm{s}: \mathrm{g}\end{array}$ & $\begin{array}{c}\text { Acceleration at } \\
16 \mathrm{~m} / \mathrm{s}: \mathrm{g}\end{array}$ & $\begin{array}{c}\text { Acceleration at } \\
18 \mathrm{~m} / \mathrm{s}: \mathrm{g}\end{array}$ & $\begin{array}{c}\text { Acceleration at } \\
20 \mathrm{~m} / \mathrm{s}: \mathrm{g}\end{array}$ & $\begin{array}{c}\text { Acceleration at } \\
22 \mathrm{~m} / \mathrm{s}: \mathrm{g}\end{array}$ & $\begin{array}{c}\text { Acceleration at } \\
24 \mathrm{~m} / \mathrm{s}: \mathrm{g} \\
\end{array}$ \\
\hline 1.0 & 0.08 & $0.20^{*}$ & 0.06 & $0.27^{*}$ & $0.20^{*}$ & 0.17 & 0.14 \\
\hline 1.5 & 0.06 & 0.17 & 0.05 & 0.22 & 0.15 & 0.13 & 0.12 \\
\hline 2.0 & 0.10 & 0.32 & 0.09 & 0.42 & 0.26 & 0.25 & 0.24 \\
\hline 2.5 & 0.08 & 0.25 & 0.07 & 0.33 & 0.20 & 0.20 & 0.19 \\
\hline 3.0 & 0.14 & 0.41 & 0.15 & 0.61 & 0.34 & 0.39 & 0.37 \\
\hline 3.5 & 0.10 & 0.21 & 0.14 & 0.47 & 0.26 & 0.33 & 0.31 \\
\hline 4.0 & 0.18 & 0.11 & 0.31 & 0.77 & 0.46 & 0.74 & 0.64 \\
\hline 4.5 & 0.13 & 0.05 & 0.20 & 0.41 & 0.33 & 0.80 & 0.61 \\
\hline 5.0 & 0.21 & 0.21 & 0.22 & 0.11 & 0.49 & $1.58^{*}$ & 0.82 \\
\hline 5.5 & 0.15 & 0.21 & 0.12 & 0.31 & 0.38 & 0.89 & 0.45 \\
\hline 6.0 & 0.24 & 0.39 & 0.16 & 0.77 & 0.67 & 1.14 & 0.70 \\
\hline
\end{tabular}

parameters are set as follows: $L=2000, p=5, h_{p}=5, h_{c}=5$, and $\mathbf{R}$ and $\mathbf{Q}$ are unity matrices. Afterwards, each control law is acted on the aircraft at corresponding test velocity. The results are shown in Table 4.

In this case, the deflection of aileron is less than 2 degrees at the whole test condition. The bold star mark denotes that the closed-loop response is larger than that of the open-loop one. From this table, it can be seen that the controller does not alleviate the wing tip response at some low frequencies. It may be caused by the turbulence at low frequencies. From Figure 3, in the real wind tunnel test, the PI controller does not alleviate gust response at these frequencies, either. At the low or high frequencies, we have to develop other excellent control methods. Note that the data length for identification may influence the alleviation effect.

3.4. Gust Response Alleviation at Varying Velocities. In the above section, we identify a unified AR model at a specified flow velocity. Hence, we need to use 7 different AR models for GPC design on the total 77 test conditions. This will save the switch time in the real test. In this section, we still want to merge the discrete data into one data segment at several test conditions. Other than identifying AR models for varying frequencies, alternatively, we identify the AR model for varying velocities at the same gust frequency. In this case, the amplitude of gust disturbance varies with flow velocities. Pointed out in Section 2.2, it is represented by the polynomials of flow velocity, and the gust frequency is fixed for a specific AR model. At a specific gust frequency $\omega_{0}$, the gust input is written as

$$
\mathbf{u}_{d}(k)=\left[\sin \omega_{0} t(k), V_{i} \sin \omega_{0} t(k), V_{i}^{2} \sin \omega_{0} t(k)\right]^{T},
$$

where $V_{i}$ is the flow velocity; it ranges from $12 \mathrm{~m} / \mathrm{s}$ to $24 \mathrm{~m} / \mathrm{s}$. A significant change on the standard GPC method is to increase the dimension of gust disturbance from one to three. Together with merged experimental response, the specific identified AR model can be adaptive to varying velocities. There are total of 11 different gust frequencies in the test. Hence, we have to identify 11 different AR models. By this approach, at each gust frequency in the wind tunnel test, we use the same AR model for gust alleviation. Therefore, we do not need to change the parameters of $\mathbf{T}, \mathbf{B}, \mathbf{A}, \mathbf{D}_{p}$, and $\mathbf{D}_{f}$ at the same gust frequency. It may save the experimental time of switching controllers at different test conditions. The length of each data segment for identification is chosen as 2000. Simulation results indicate that this data length will result in better alleviation effect. The other parameters are set the same as above. Table 5 shows the gust response alleviation results at each test condition for varying velocities. The bold star infers that the closed loop response is not alleviated by the controller.

From this table, it can be seen that this controller suppresses most of the response. However, the closed-loop response is larger than the open-loop one at 2 test conditions. The amplified closed-loop response mainly occurs at very low and very high frequencies, similar to the results by the PI controller. At these test conditions, the gust frequency is far away from its frequency of first bending mode, which is about $3 \mathrm{~Hz}$.

3.5. Gust Alleviation at Varying Flow Velocities and Gust Frequencies. In this section, we merged the whole inputoutput data to one data series to identify only one AR model. There are total of seven different flow velocities. And, at each velocity, there are 11 different frequencies. Hence, a total 77 varying open-loop responses are used to identify a unified AR model. The first 0.6 seconds of each data segment is chosen to compose the total 46.2 seconds open-loop response data. A fifth-order AR model with 3 gust inputs is identified by the linear square algorithm. The comparison of experimental open-loop response and identified acceleration is shown in Figure 7. Figure 7(a) shows the response comparison for lower frequency at varying flow velocity. Figure 7(b) shows the response comparison for higher frequency. From the comparison, it can be seen that though the order of AR model is only five, the experimental response can also agree well with the identified one under varying flow velocities. The identified model can describe the aircraft model's aeroelastic behavior well. Noting that there is some disturbance when 
TABLE 5: Gust response alleviation result for fixed frequency and varying velocities.

\begin{tabular}{|c|c|c|c|c|c|c|c|}
\hline Frequency: Hz & $\begin{array}{c}\text { Acceleration at } \\
12 \mathrm{~m} / \mathrm{s}: \mathrm{g}\end{array}$ & $\begin{array}{c}\text { Acceleration at } \\
14 \mathrm{~m} / \mathrm{s}: \mathrm{g}\end{array}$ & $\begin{array}{c}\text { Acceleration at } \\
16 \mathrm{~m} / \mathrm{s}: \mathrm{g}\end{array}$ & $\begin{array}{c}\text { Acceleration at } \\
18 \mathrm{~m} / \mathrm{s}: \mathrm{g}\end{array}$ & $\begin{array}{c}\text { Acceleration at } \\
20 \mathrm{~m} / \mathrm{s}: \mathrm{g}\end{array}$ & $\begin{array}{c}\text { Acceleration at } \\
22 \mathrm{~m} / \mathrm{s}: \mathrm{g}\end{array}$ & $\begin{array}{c}\text { Acceleration at } \\
24 \mathrm{~m} / \mathrm{s}: \mathrm{g}\end{array}$ \\
\hline 1.0 & $0.13^{*}$ & 0.07 & 0.03 & 0.01 & 0.03 & 0.07 & 0.14 \\
\hline 1.5 & 0.13 & 0.12 & 0.09 & 0.06 & 0.07 & 0.14 & 0.24 \\
\hline 2.0 & 0.56 & 0.16 & 0.24 & 0.47 & 0.62 & 0.70 & 0.73 \\
\hline 2.5 & 0.20 & 0.11 & 0.16 & 0.19 & 0.18 & 0.13 & 0.19 \\
\hline 3.0 & 0.41 & 0.23 & 0.35 & 0.45 & 0.68 & 1.21 & $2.02^{*}$ \\
\hline 3.5 & 0.26 & 0.05 & 0.05 & 0.05 & 0.14 & 0.40 & 0.78 \\
\hline 4.0 & 0.22 & 0.11 & 0.27 & 0.25 & 0.14 & 0.40 & 0.94 \\
\hline 4.5 & 0.28 & 0.04 & 0.16 & 0.21 & 0.22 & 0.40 & 0.77 \\
\hline 5.0 & 0.03 & 0.19 & 0.26 & 0.29 & 0.40 & 0.67 & 1.10 \\
\hline 5.5 & 0.20 & 0.19 & 0.32 & 0.33 & 0.21 & 0.20 & 0.57 \\
\hline 6.0 & 0.30 & 0.32 & 0.28 & 0.19 & 0.30 & 0.68 & 1.22 \\
\hline
\end{tabular}

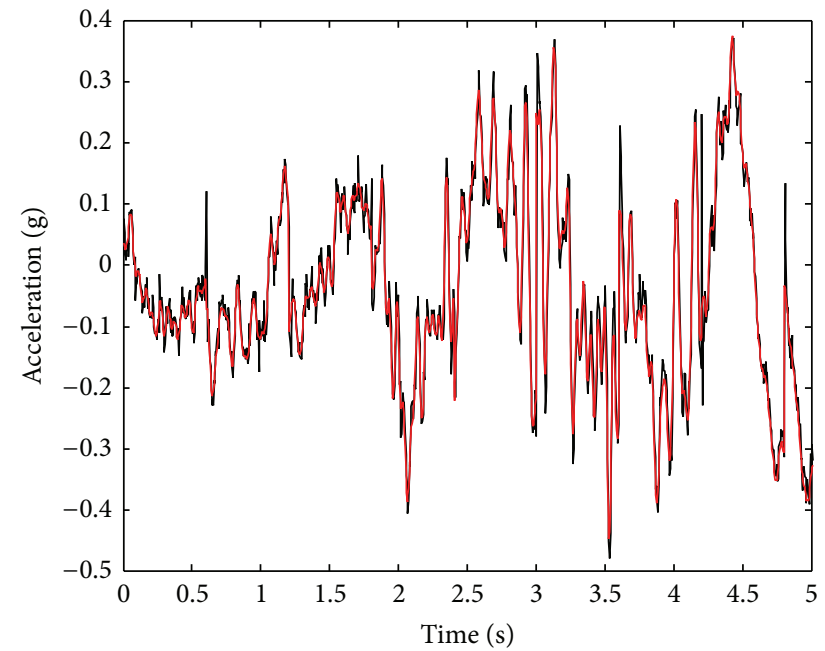

_ Experimental open-loop response

- Identified open-loop response

(a) Response at the first 5 seconds

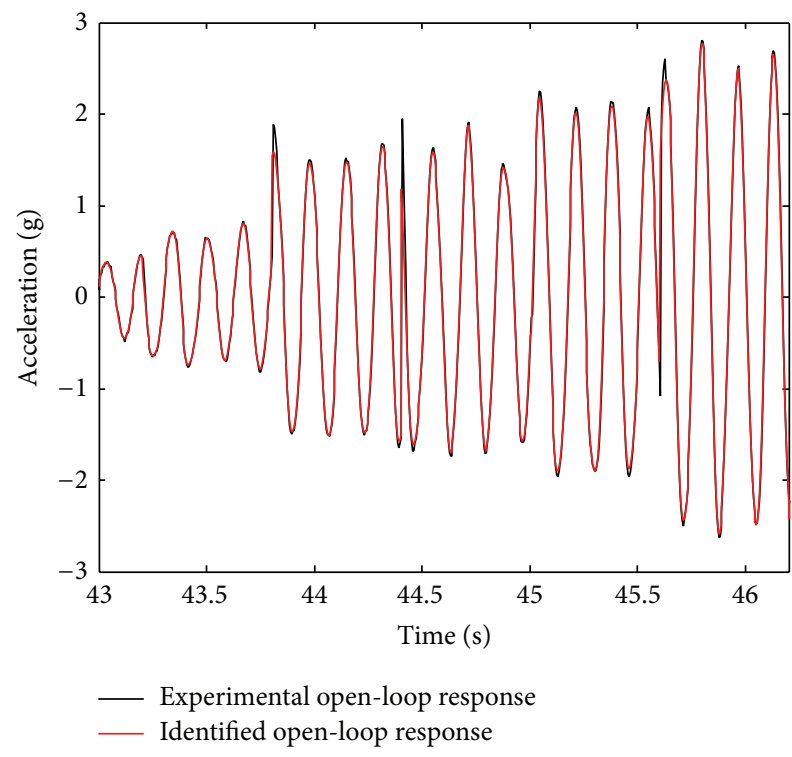

(b) Response at the last 5 seconds

FIGURE 7: The comparison between the experimental response and the output of identified AR model.

the gust frequency is only $1 \mathrm{~Hz}$, the response of identified model in the low frequency may have some discrepancies from the experimental one, indicated in Figure 7(a). Noting that alleviation factor may fluctuate with the length of each data segment, 0.6 -second data here is enough to get a not bad alleviation result.

After a unified AR model is identified using the 77 pieces of test data, the modified GPC controller is applied to gust response alleviation at all the experimental conditions. The amplitude of closed-loop response is shown in Table 6. From this table, it can be seen that the modified GPC controller is effective at all the test conditions. Comparing it with the open-loop response shown in Table 1, the alleviation factor can be up to $20 \%$ for all the test conditions. The closed-loop response and aileron's deflection are shown in Figure 8. It is compared with the experimental one at the velocity of $24 \mathrm{~m} / \mathrm{s}$ and the gust frequency of $6 \mathrm{~Hz}$. Though there is a shock at the time of controller acting on the aircraft model, the deflection does not reach 0.5 degrees all the time. It needs only a little control effort to alleviate the wing tip acceleration.

\section{Conclusions}

The gust response alleviation of an aircraft model is developed with the modified GPC design algorithm. The simulated closed-loop response by GPC is compared with experimental results of the sinusoidal gust response test in the wind tunnel. In order to adapt the controller to varying experimental flow velocity, the gust disturbance is represented by second-order polynomials of flow velocities. Consequently, the influence of varying gust input on the AR model is considered. 
TABLE 6: Gust response alleviation result for varying frequencies and varying velocities.

\begin{tabular}{|c|c|c|c|c|c|c|c|}
\hline Frequency: $\mathrm{Hz}$ & $\begin{array}{c}\text { Acceleration at } \\
12 \mathrm{~m} / \mathrm{s}: \mathrm{g}\end{array}$ & $\begin{array}{c}\text { Acceleration at } \\
14 \mathrm{~m} / \mathrm{s}: \mathrm{g}\end{array}$ & $\begin{array}{c}\text { Acceleration at } \\
16 \mathrm{~m} / \mathrm{s}: \mathrm{g}\end{array}$ & $\begin{array}{c}\text { Acceleration at } \\
18 \mathrm{~m} / \mathrm{s}: \mathrm{g}\end{array}$ & $\begin{array}{c}\text { Acceleration at } \\
20 \mathrm{~m} / \mathrm{s}: \mathrm{g}\end{array}$ & $\begin{array}{c}\text { Acceleration at } \\
22 \mathrm{~m} / \mathrm{s}: \mathrm{g}\end{array}$ & $\begin{array}{c}\text { Acceleration at } \\
24 \mathrm{~m} / \mathrm{s}: \mathrm{g} \\
\end{array}$ \\
\hline 1.0 & 0.03 & 0.01 & 0.01 & 0.02 & 0.05 & 0.09 & 0.14 \\
\hline 1.5 & 0.02 & 0.01 & 0.01 & 0.02 & 0.03 & 0.06 & 0.09 \\
\hline 2.0 & 0.03 & 0.02 & 0.02 & 0.03 & 0.05 & 0.09 & 0.14 \\
\hline 2.5 & 0.02 & 0.01 & 0.01 & 0.02 & 0.03 & 0.06 & 0.09 \\
\hline 3.0 & 0.04 & 0.03 & 0.03 & 0.03 & 0.05 & 0.09 & 0.15 \\
\hline 3.5 & 0.03 & 0.02 & 0.02 & 0.02 & 0.03 & 0.07 & 0.12 \\
\hline 4.0 & 0.05 & 0.04 & 0.04 & 0.03 & 0.05 & 0.12 & 0.23 \\
\hline 4.5 & 0.04 & 0.03 & 0.03 & 0.02 & 0.04 & 0.10 & 0.20 \\
\hline 5.0 & 0.07 & 0.05 & 0.06 & 0.03 & 0.07 & 0.20 & 0.39 \\
\hline 5.5 & 0.05 & 0.04 & 0.05 & 0.02 & 0.05 & 0.16 & 0.31 \\
\hline 6.0 & 0.07 & 0.06 & 0.08 & 0.03 & 0.08 & 0.27 & 0.52 \\
\hline
\end{tabular}

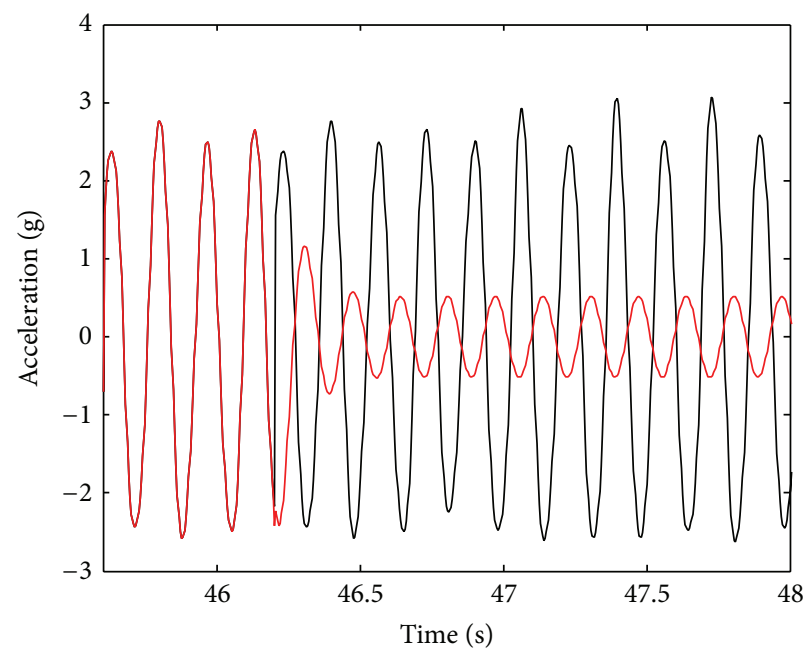

_ Experimental open-loop response

- Closed-loop response

(a)

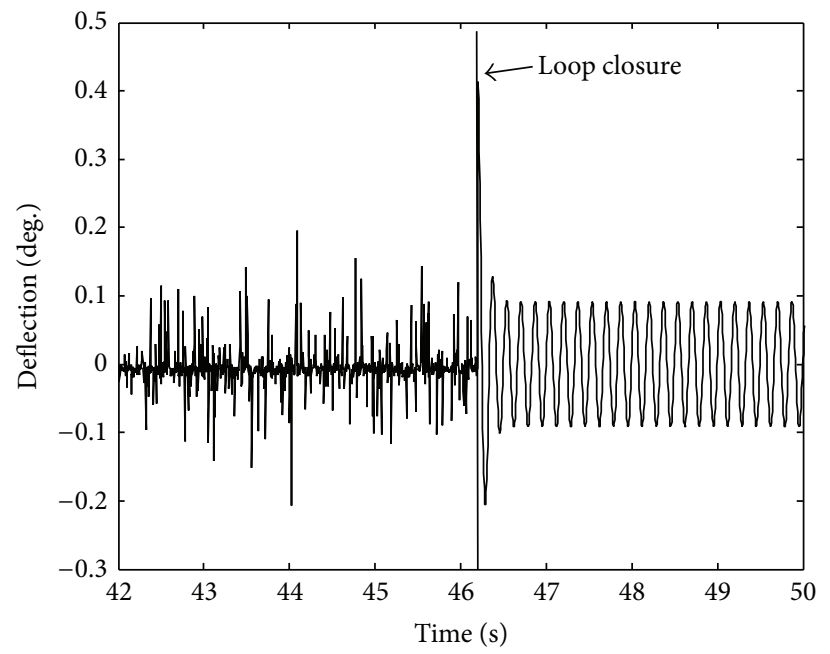

(b)

FIGURE 8: The closed-loop response (a) and the deflection of aileron (b).

By the wind tunnel test and closed-loop response simulations, some conclusions are made as follows:

(1) The standard GPC can be applied to gust response alleviation in the wind tunnel test. Compared with model-based method, there is no need to construct a theoretical aeroelastic model by the data-based GPC method. It can suppress the wing tip response significantly at high frequencies. However, it does not work well at some low frequencies.

(2) The modified GPC design algorithm can be adapted to varying flow velocities and frequencies. It is advantageous in the wind tunnel test that we do not need to switch the control law in the whole test. It may save the wind tunnel test time. The modified GPC controller is acted on the experimental open-loop acceleration data. Simulation indicates that the unified controller can alleviate the wing tip accelerations up to $20 \%$. Note that the alleviation effect may fluctuate with different parameters chosen in the model identification process.

\section{Conflict of Interests}

The authors declare that there is no conflict of interests regarding the publication of this paper.

\section{Acknowledgments}

This work was supported by the National Natural Science Foundation of China (no. 11302011 and 11172025) and the Research Fund for the Doctoral Program of Higher Education of China (no. 20131102120051). 


\section{References}

[1] M. Karpel, B. Moulin, and P. C. Chen, "Dynamic response of aeroservoelastic systems to gust excitation," Journal of Aircraft, vol. 42, no. 5, pp. 1264-1272, 2005.

[2] M. Karpel and B. Moulin, "Gust loads alleviation using special control surfaces," Journal of Aircraft, vol. 44, no. 1, pp. 17-25, 2007.

[3] M. Karpel, B. Moulin, E. Presente et al., "Dynamic gust loads analysis for transport aircraft with nonlinear control effects," AIAA 2008-1994, 2008.

[4] T. E. Disney, "C-5A active load alleviation system," Journal of Spacecraft and Rockets, vol. 14, no. 2, pp. 81-86, 1977.

[5] J. Mckenzie, "B-52 control configured vehicles ride control analysis and flight test," in Proceedings of the 5th Aircraft Design, Flight Test and Operations Meeting, AIAA 73-782, 1973.

[6] B. Winther, W. Shirley, and R. Heimbaugh, "Wind-tunnel investigation of active control technology applied to a DC-10 deribative," AIAA 80-0771, 1980.

[7] L. Chen, Z. Wu, C. Yang et al., "Gust response, load alleviation and wind-tunnel experiment verification of elastic wing," Acta Aeronautica et Astronautica Sinica, vol. 30, no. 12, pp. 22502256, 2009.

[8] Z. Wu, L. Chen, and C. Yang, "Study on gust alleviation control and wind tunnel test," Science China Technological Sciences, vol. 56, no. 3, pp. 762-771, 2013.

[9] J. M. Martín-Sánche, J. M. Lemos, and J. Rodellar, "Survey of industrial optimized adaptive control," International Journal of Adaptive Control and Signal Processing, vol. 26, no. 10, pp. 881918, 2012.

[10] Y. Matsuzaki, "An overview of flutter prediction in tests based on stability criteria in discrete-time domain," International Journal of Aeronautical and Space Sciences, vol. 12, no. 4, pp. 305-317, 2011.

[11] J. V. Salcedo, M. Martínez, C. Ramos, and J. M. Herrero, "GPCLPV: a predictive LPV controller based on BMIs," in Proceedings of the 44th IEEE Conference on Decision and Control, and the European Control Conference (CDC-ECC '05), pp. 4311-4317, IEEE, Seville, Spain, December 2005.

[12] R. Kvaternik, K. Eure, and J. Juang, "Exploratory studies in generalized predictive control for active gust load alleviation," Tech. Rep. NASA/TM-2006-214296, 2006.

[13] J.-S. Lew and J.-N. Juang, "Robust generalized predictive control with uncertainty quantification," Journal of Guidance, Control, and Dynamics, vol. 35, no. 3, pp. 930-937, 2012.

[14] Z. Wu, Y. Dai, C. Yang, and L. Chen, "Aeroelastic wind-tunnel test for aerodynamic uncertainty model validation," Journal of Aircraft, vol. 50, no. 1, pp. 47-55, 2013. 

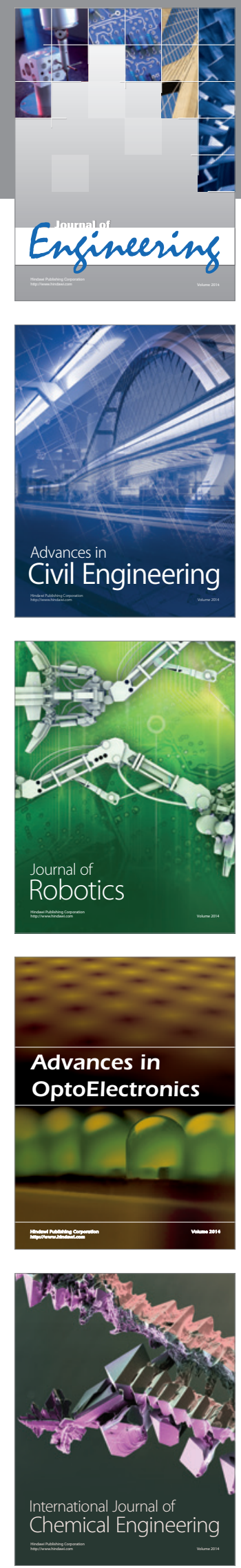

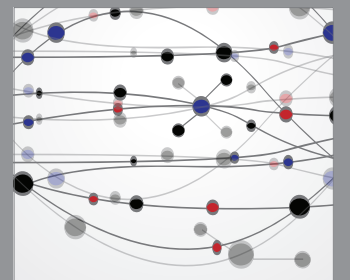

The Scientific World Journal
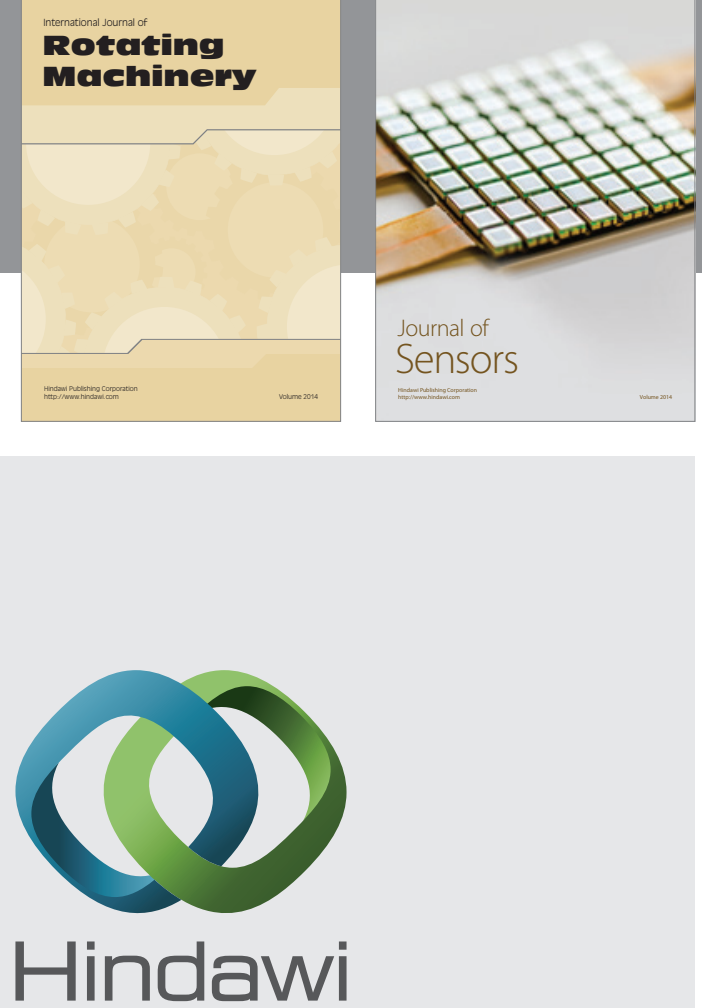

Submit your manuscripts at http://www.hindawi.com
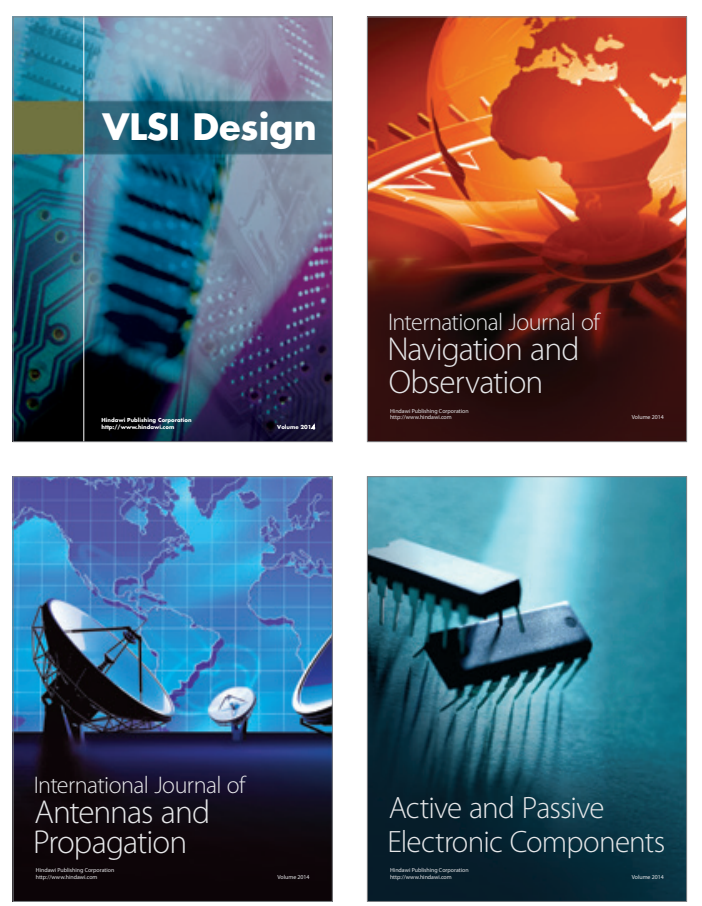
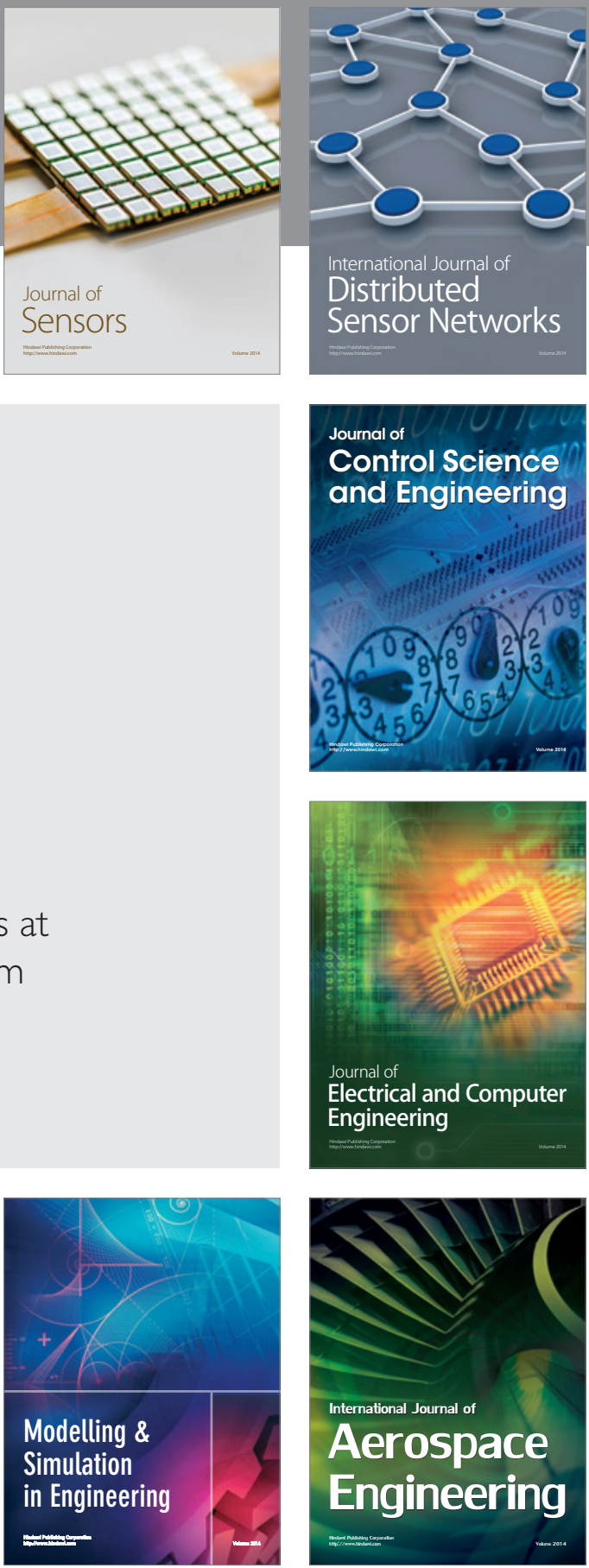

Journal of

Control Science

and Engineering
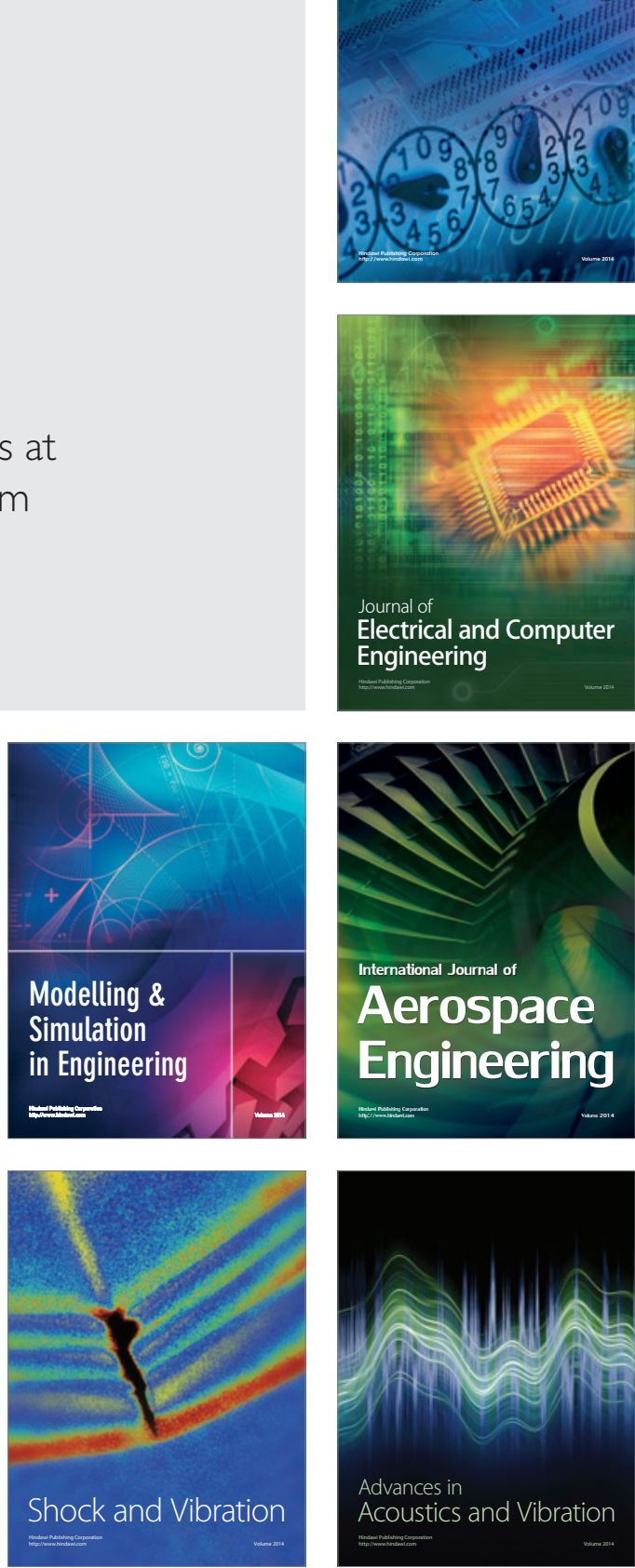